\title{
Initial Design Development of Performance Assessment Methods in Planimetry Lectures
}

\author{
I Putu Wisna Ariawan* and I Made Ardana
}

\author{
Department of Mathematics Education, Ganesha University of Education, Bali, Indonesia \\ *Corresponding author. Email: wisna.ariawan@undiksha.ac.id
}

\begin{abstract}
This study aims to find a suitable format for performance assessment methods applied to planimetry lectures which are expected to improve student learning outcomes. The final product expected from this research is the design of a performance assessment method that can be applied to planimetry lectures. In this study, the research and development method was used. The development design used is the Borg and Gall (2008) model which only adopts 5 steps from the 10 steps of the Borg and Gall model. The subjects involved in this study consisted of 3 experts who gave assessments related to the validity and practicality of the product developed based on the questionnaire given with a score range of 1 to 4 on each item, 10 students (who received treatment) who gave an assessment related to the practicality of the product developed based on a questionnaire given with a score range of 1 to 4 on each item. Based on the development results, the product specifications for the performance assessment method consist of: Tasks that must be completed, the Design of Activities to Complete Tasks, and Rubrics for assessing Tasks that must be completed to assess the process and product of the task. Based on the preliminary test results on the performance assessment model developed, it can be concluded that the performance assessment model developed in the planimetry course is valid and can be used in the planimetry learning process.
\end{abstract}

\section{Keywords: performance assessment method, planimetry, student learning outcomes}

\section{INTRODUCTION}

Apart from being a basic science, mathematics is also a means that can be used to develop critical thinking skills because according to [1], mathematics is essentially a human way of thinking. Given the important role of mathematics, it is necessary to make an effort to improve the quality of mathematics education. One that can be used as an indicator of the quality of mathematics education is the learning outcomes achieved by students because these learning outcomes reflect the success of students or students in taking education. The question that immediately arises today is that with the Covid-19 pandemic that has hit almost all countries in the world, will the quality of mathematics education be maintained?

The Covid-19 pandemic has had a tremendous impact on the order of human life, not only in Indonesia but in almost all countries in the world. All aspects of life are changed, including the aspect of education. In the aspect of education, which is actually intended to educate future generations, it has also undergone drastic changes. [2] said there are four ways Covid-19 has changed the way we educate future generations.
First, that educational processes around the world are increasingly interconnected. Second, redefining the role of educators. Third, teach the importance of life skills in the future. And, fourth, to broaden the role of technology in supporting education. In addition, [3] stated that the Covid-19 pandemic caused three fundamental changes in global education. First, changing the way millions of people are educated. Second, new solutions for education that can bring about much-needed innovation. Third, the existence of a digital divide causes new shifts in educational approaches and can widen the gap. The outbreak of Covid-19 caused the world of education to be 'forced' tochange direction to change the face-to-face learning methodology to online learning. ([4], [5]).

One of the impacts felt as a result of online learning is that assessments for students may have measurement errors, unlike the usual measurements [6]. In addition, online learning using e-learning is not always effective in seeing the quality of education quality if it is only used to measure the cognitive realm [7]. Therefore, in the learning process there must be instructional interventions and innovations from teachers in 
managing the learning process to improve learning outcomes.

In normal conditions, prior to the spread of the Covid19 outbreak, student learning outcomes, especially in the Field Geometry course, were not satisfactory. In the 2019/2020 odd semester the average student learning outcomes for the Final Semester Examination only reached 38.75. Of course, this result is still far from being expected. What's more, with the outbreak of Covid-19 which causes the lecture process to be conducted online, of course the learning outcomes in this course are questionable. For this reason, in the lecture process there must be instructional intervention and innovation from course instructors to improve student learning outcomes in field geometry courses. One of the instructional and innovative interventions that can be done is the use of the assessment method, especially the formative assessment method used by teachers so far. The formative assessment method that is intended is the method used by the teacher to implement the assessment that has been prepared for formative purposes. The formative assessment method used so far is more conventional, using only descriptive tests.

Performance assessment as a formative assessment method really needs to be considered in its use in field geometry courses. What's more, based on the results of the author's research in 2016, it turns out that the results of the Transformation Geometry learning group of students who were given performance assessments were higher than those given conventional assessments.

Based on the description above, it is necessary to look for an assessment format, especially what kind of performance assessment method should be applied to planimetry lectures which can improve student learning outcomes? To answer this question, it is considered important and urgent to conduct research with the title "Development of Performance Assessment Methods in Planimetry Lectures to Improve Student Learning Outcomes.

Planimetry as a part of mathematics certainly also has characteristics as a pure mathematical science and as part of school mathematics. Mathematics education students as prospective teachers who will teach materials on planimetry must be able to distinguish the two essences. Even though the material to be taught to students later is not as "strict" as pure mathematics material, students need to also be equipped with abilities related to the essence of planimetry as a part of pure mathematics. This is intended so that the prospective mathematics teacher who is born truly has adequate professional competence, especially in the aspect of mastery of planimetry.

Planimetry as a pure science in which there is a system called an axiomatic system starting from the elements and the root relations, axioms to theorems / theorems and their consequences. The system is very abstract. This abstract axiomatic system also has consequences at the level of content of planimetry material that students must be able to understand. The content of the material in planimetry is more predominantly colored by axiomatic system in the form of theorems whose truth must be proven in a logical and systematic flow of proof process. Sometimes it is not easy for students to understand a theorem even though the evidence has been presented explicitly. Of course the level of difficulty will increase when students have to prove a theorem by themselves because they have to make correct arguments and are arranged in a logical sequence.

According to [8], assessment is the process of documenting the skills and development of students. Furthermore, it is explained that assessment is a way to assess the performance of students individually and in groups after learning is carried out. This opinion, according to [9] is supported by Gronlund and Linn, which defines assessment in general terms that involve all a series of procedures used to obtain information about student learning outcomes (for example: observations, multilevel scales of performance, tests written) and the implementation of an assessment of the learning progress of students. Meanwhile, [10] define assessment as a process to obtain information in any form that can be used as a basis for decision making. The definition of assessment is almost the same as the notion of evaluation, but assessment places a greater emphasis on the performance of tasks in real and complex forms.

The opinions above clearly show that assessment is an important part and needs to be considered in learning. In order to determine the success of a learning process, an absolute assessment must be carried out. Thus, the assessment activity is an inseparable part of the learning process. This is confirmed by the statement of [11] that assessment is an important component of instructions and statements [12] that student assessment is one of the most important responsibilities of teachers, because the quality of teaching in the classroom is closely related to the quality of the assessment applied.

In relation to formative assessment and summative assessment, [13] state that formative assessment is carried out to monitor learning progress during the learning process while summative assessment is carried out to assess learning achievement at the end of learning. Meanwhile, [14] states that although an assessment can be designed or packaged such as a formative assessment or summative assessment, it is only a methodology, data analysis and utilization of the results will determine whether an assessment is formative or summative.

Based on the assessment method used, [15] states, there are four main categories of assessment methods, namely: written assessments, performance assignments, senior projects, and portfolios. Meanwhile, [16] state that the current assessment varies widely, but always falls within one of the basic assessment methods, namely: selected response and short answer (selected response and short answer), extended written response (extended written response), performance assessment (performance assessment), and personal communication (personal communication). Based on the above 
opinions, the description test and performance assessment are two different assessment methods that can be used as a formative assessment method in the learning process of the planimetry course.

Performance assessment is a formative assessment method that invites students to think more broadly and deeply about a case. According to [17] performance assessment is an assessment that requires students to demonstrate performance instead of answering or choosing answers from the alternative answers that have been provided. Furthermore, [17] argued that in principle, performance assessment consists of two parts, namely tasks and criteria. Performance tasks can be in the form of a project, exhibition, portfolio or assignments that require students to demonstrate performance abilities. According to [10] performance assessment tasks can be realized in the form of: computer adaptive testing, extended multiple choice tests, extended-response or open-ended questions, group performance assessments, individual performance assessments, interviews, observations, portfolios , projects, exhibition, short answers and so on.

According to [18] performance assessment is a form of assessment that allows students to demonstrate a series of skills or behaviors, products in a certain context. Marhaeni said that performance assessment is tracing products in process. This means that the results of the work shown in the program implementation process are used as the basis for monitoring the progress of one program's achievement.

Performance assessment is an assessment that emphasizes what students can do in the form of performance. Performance assessment is carried out by observing the activities or performance of students in doing something. The objectives of the performance assessment are as follows.

(1) Diagnosing the strengths and weaknesses of students in learning

(2) Monitor the progress or development of students Determine the level or level of students' ability to comply with public perceptions of the effectiveness of learning

(3) Evaluating the performance of teachers / lecturers and classifying learning objectives formulated by the teacher / lecturer.

The main characteristic of performance assessment is not only measuring the learning outcomes of students, but providing more clear information about the learning process. In other words, performance assessment is a process that accompanies all learning and learning activities in a way that students demonstrate their performance. As [19] argues, performance assessment is a tool to improve teacher teaching and student learning. Performance assessment in mathematics learning is not exactly the same as performance assessment in other fields. This is because the field of mathematics has a different character from other fields. This is in accordance with statement [15] which states that performance assessment in mathematics is more in the form of solving problems with paper-pencils and calculators, expressing relationships in various forms such as graphs, and others. Likewise, performance assessment in art includes performance in music, dance, drawing, and so on. In language, performance assessment tends to focus on the words written, read, understand, interpret, compare, produce text to describe, explain, persuade, and others.

According to [17] there are two important components in the assessment, namely performance tasks and performance rubrics. Task is the tasks that will be carried out to make a performance assessment, while the rubric consists of a list of criteria manifested by the dimensions of work, process aspects or concepts to be assessed and quality gradations starting from the most perfect level to the worst level. Based on the description above, the product specification in the form of a performance assessment method that is designed must contain: tasks that must be completed, the design of activities carried out in completing the task, and a rubric for assessing the tasks that must be completed to assess the process. and workmanship products. This study aims to find a format for a performance assessment method that is valid, practical, efficient and suitable for application in planimetry courses that can improve student learning outcomes. The final product expected from this research is the design of a performance assessment method that can be applied to planimetry lectures.

\section{METHODOLOGY}

This research is included in the category of research and development (Research and Development). The development design used is the [20] which only adopts 5 steps from the 10 steps of the Borg and Gall model. In the early stages of this research was only carried out until the 5th stage which includes: 1) research and field data collection (research and information collection), 2) planning research (planning), 3). design development (develop preliminary form of product), 4). preliminary field test, and 5). revision of the initial test results (main product revision). According to [21], the design product of the performance assessment method is said to have good quality, if it meets the criteria of validity, practicality, and effectiveness. The implementation of these five stages is intended to obtain validity and practicality of the performance assessment method being developed. The subjects involved in this study consisted of 3 experts who would provide an assessment related to the validity and practicality of the performance assessment method developed based on a questionnaire given with a score range of 1 to 4 on each item, 10 students (who received treatment) which will provide an assessment related to the practicality of the performance assessment method developed based on a questionnaire given with a score range of 1 to 4 on each item. 
If $\bar{P}$ is the average rating given by the validator, then the criteria used to determine its validity are:

$3 \leq \bar{P} \leq 4$ states the device is valid

$2 \leq \bar{P}<3$ indicates that the device is quite valid

$1 \leq \bar{P}<2$ indicates invalid device

Modified from [22].

In addition, according to [22], the performance assessment method developed is said to be valid if more than half (at least $51 \%$ ) of the validators state that the design product of the performance assessment method developed is at least in the category "supported by a fairly strong theory".

To see the practicality of the performance assessment method developed, it will be seen from the responses given by experts (validators) and students. If $\bar{V}$ (in percent) states the mean of the three validators and $\bar{M}$ (in percent) states the average response given by students on the practical aspect, then the practicality value is calculated using the formula $\mathrm{KM}=\frac{\bar{V}+\bar{M}}{2}$. The criteria used to determine practicality are:

$\mathrm{KM} \geq 75 \%$ : applicable without revision

$50 \% \leq \mathrm{KM}<75 \%$ : applicable with minor revisions

$25 \% \leq \mathrm{KM}<50 \%$ : can be applied with many revisions

$\mathrm{KM}<25 \%$ : not applicable

Modified from [22]:

\section{RESULTS AND DISCUSSION}

Performance assessment in mathematics learning is not exactly the same as performance assessment in other fields. This is because the field of mathematics has a different character from other fields. Performance assessment in mathematics is more in the form of solving problems with paper-pencils and calculators, expressing relationships in various forms such as graphs, and others [15]. There are two important components in assessment, namely the performance task and the performance rubric [17]. Task is the tasks that will be carried out to make a performance assessment, while the rubric consists of a list of criteria manifested by the dimensions of work, process aspects or concepts to be assessed and quality gradations starting from the most perfect level to the worst level. Based on the description above, the product specifications in the form of a performance assessment method designed must contain: tasks that must be completed, the design of activities carried out in completing the task, and a rubric for assessing tasks that must be completed to assess the process. Initial design of the performance assessment method in the planimetry lecture being developed is presented in the following figure.

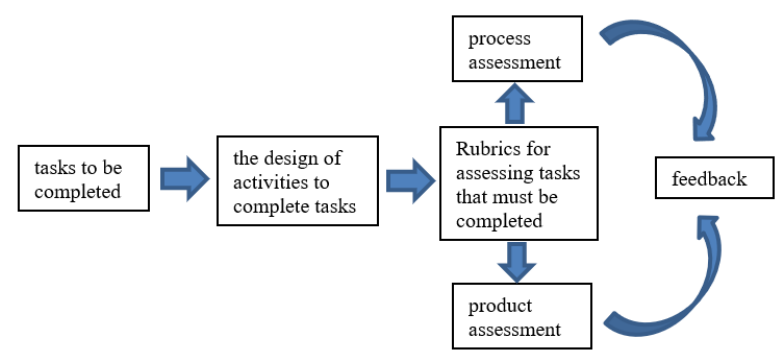

Figure 1 Product specifications design performance assessment methods that have been developed

One example of a given task is:

to find, what concept distinguishes between congruence and similarity about two triangles.

The final product expected from this task is that students must be able to first identify that the concept of congruence and similarity between two triangles requires:

1. The same angle measures of the corresponding angles of two triangles

2 . The equality of the ratio between the corresponding pair of sides of the two triangles.

The concept that distinguishes it lies in the ratio between the corresponding pair of sides of the two triangles. In the concept of congruence the ratio must be equal to one. Meanwhile, in the concept of similarity the value does not have to be equal to one. To complete this task, student activities such as student discussions with other students are assessed. Based on the results of student work and the activities carried out in completing the task, the lecturer provides feedback, especially on errors in task execution and student discussion activities. To clarify the visualization, the lecturer uses Geogebra media like the following illustration.
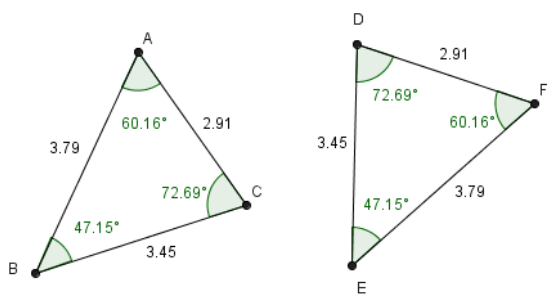

(a)
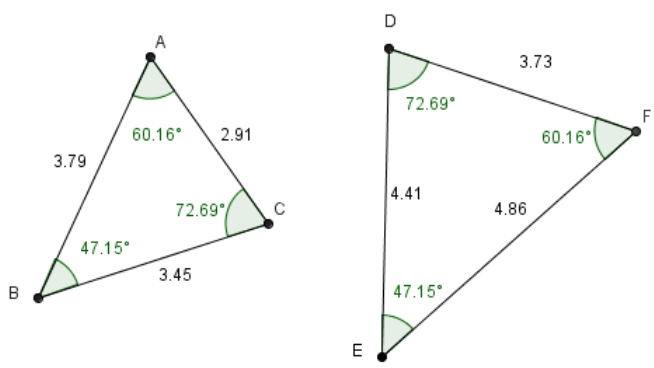

(b)

Figure 2 Illustration of Congruence and Similarity Using Geogebra 
Figure 2 (a) shows the concept of congruence where $\triangle \mathrm{ABC}$ congruence to $\triangle \mathrm{FED}$ because $\angle \mathrm{A}=\angle \mathrm{F}, \angle \mathrm{B}=$ $\angle \mathrm{E}, \angle \mathrm{C}=\angle \mathrm{D}$ and $\frac{A B}{F E}=\frac{B C}{E D}=\frac{A C}{F D}=1$ while Figure $2(\mathrm{~b})$ shows the concept of similarity where $\triangle \mathrm{ABC}$ similar to $\triangle \mathrm{FED}$ because $\angle \mathrm{A}=\angle \mathrm{F}, \angle \mathrm{B}=\angle \mathrm{E}, \angle \mathrm{C}=\angle \mathrm{D}$ and $\frac{A B}{F E}=$ $\frac{B C}{E D}=\frac{A C}{F D}=0,78$.

For expert validation tests on the Performance assessment model developed, the questionnaire given is divided into two parts, namely: the first part is related to the Supporting Theory for the Assessment Model (consisting of 2 items), the second part is related to the Components of the Assessment Model (consisting of 10 items) . Meanwhile, the student response to the Performance Assessment Model developed consists of 8 items. Based on the results of the questionnaire tabulation, the mean of the results of the expert validation test on the performance assessment model developed reached a mean of 3.33 and the three validators also stated that the design product of the performance assessment method developed was in the category "supported by a fairly strong theory". Meanwhile, the student's response to the performance assessment model developed reached a mean of 3.34. Based on the results of the questionnaire tabulation, the average response of the experts to the Performance Assessment Model developed was 3.33. Based on the criteria developed by [22] to determine the validity of the developed model then the performance assessment model developed is valid. In addition, the three validators also stated that the design product of the performance assessment method developed was in the category "supported by a fairly strong theory". In the practicality aspect, from the validator's assessment, the three validators gave the consideration that the performance assessment method design developed was in the category "can be applied with a few revisions". From the student's point of view, the mean value is 3.34 if converted to the criteria for determining the feasibility of the performance assessment method design developed according to student assessment, the result is $83.50 \%$. This assessment falls into the category "applicable without revision". By considering the results of the validator and student assessment, the results obtained in the practicality aspect (level of implementation of the design of the performance assessment method developed), $\mathrm{KM}=$ $91.75 \%$, which means that it is in the "applicable" category. without revision".

\section{CONCLUSION}

Based on the preliminary test results of the Performance Assessment Model Developed, it can be concluded that the Performance Assessment Model developed in the planimetry course is valid and can be used in the planimetry learning process.

\section{ACKNOWLEDGMENT}

We would like to thank LPPM Undiksha for funding this research.

\section{REFERENCES}

[1] J. Kilpatrick, History of research in mathematics education. Encyclopedia of mathematics education, (2020) 349-354. DOI: https://doi.org/10.1007/978-3030-15789-0_71

[2] P. Luthra, S. Mackenzie, 4 Ways Covid-19 Education Future Generations. Source: https://www. weforum.org/agenda/2020/03/4-ways-covid-19educatio n-future-generations.

[3] G. Tam, D. El-Azar, D. 3 Ways the coronavirus pandemic could reshape education. In World Economic Forum, 2020. Source: https://www.weforum.org/agenda /2020/03/3-wayscoronavirus-is-reshaping-educationand-what-changes-might-be-here-to-stay/

[4] S. Dhawan, Online learning: A panacea in the time of COVID-19 crisis. Journal of Educational Technology Systems, 49 (1) (2020) 5-22. DOI: https://doi.org/ $10.1177 / 0047239520934018$

[5] J. Daniel, Education and the COVID-19 pandemic. Prospects, 49 (1) (2020) 91-96. DOI: https:// doi.org/10.1007/s11125-020-09464-3

[6] A. Abidah, H. N. Hidaayatullaah, R. M. Simamora, D. Fehabutar, L. Mutakinati, The impact of COVID-19 to Indonesian Education and its Relation to the philosophy of "Merdeka Belajar". Studies in Philosophy of Science and Education, 1 (1) (2020) 3849. DOI: https://doi.org/10.46627/sipose.v1i1.9

[7] I. P. W. Ariawan, D. G. H. Divayana, P. W. A Suyasa, Initial design of blended learning for mathematics subject using the Kelase platform by adopting content of Tri Kaya Parisudha. In Journal of Physics: Conference Series 1470 (1) (2020) 012009. IOP Publishing. DOI: https://doi.org/doi:10.1088/1742 $-6596 / 1470 / 1 / 012009$

[8] A. Chatzipanteli, V. Grammatikopoulos, A. Gregoriadis, Development and evaluation of metacognition in early childhood education. Early child development and care, 184 (8) (2014) 1223-1232. DOI: https://doi.org/10.1080/03004430.2013.861456

[9] P. Broadfoot*, P Black, Redefining assessment? The first ten years of assessment in education. Assessment in Education: Principles, Policy \& Practice, 11 (1) (2004) 7-26. DOI: https://doi.org/10.1080/096 9594042000208976 
[10] S. Hubalovsky, M. Hubalovska, M. Musilek, Assessment of the influence of adaptive E-learning on learning effectiveness of primary school pupils. Computers in Human Behavior, 92 (2019) 691705. DOI: https://doi.org/10.1016/j.chb.2018.05.033

[11] S. Dikli, Assessment at a distance: Traditional vs. alternative assessments. Turkish Online Journal of Educational Technology-TOJET, 2 (3) (2003) 13-19.

[12] B. Khadijeh, R. Amir, Importance of teachers' assessment literacy. International Journal of English Language Education, 3 (1) (2015) 139-146. DOI: https://doi.org/10.5296/ijele.v3i1.6887

[13] M. D. Miller, R. L. Linn, E. Norman, Gronlund, Measurement and Assesment in Theaching. 2009.

[14] K. E. Dunn, S. W. Mulvenon, A critical review of research on formative assessments: The limited scientific evidence of the impact of formative assessments in education. Practical Assessment, Research, and Evaluation, 14 (1) (2009) 7. DOI https://doi.org/10.7275/jg4h-rb87

[15] B. Stecher, Performance assessment in an era of standards-based educational accountability. Stanford Center for Opportunity Policy in Education. 2010. http://edpolicy.stanford.edu

[16] J. Chappuis, R. J. Stiggins, S. Chappuis, J. Arter, Classroom assessment for student learning: Doing it right-using it well (2012) 432. Upper Saddle River, NJ: Pearson.

[17] C. Gipps, G. Stobart, Alternative assessment. In International handbook of educational evaluation (2003) 549-575. Springer, Dordrecht. DOIhttps://doi.org/10.1007/978-94-010-0309-4_33

[18] S. H. Prayitno, M. P. D. Jaedun, Authentic assessment competence of building construction teachers in Indonesian vocational schools. Journal of Technical Education and Training 10 (1) (2018) 91108. DOI: https://10.30880/jtet.2018.10.01.008

[19] F. D. Drake, Using Alternative Assessments To Improve the Teaching and Learning of History. ERIC Digest. 1997.

[20] M. D. Gall, W. R. Borg, J. P. Gall, Educational research: An introduction. Longman Publishing. 1996.

[21] N. Nieveen, Prototyping to reach product quality. In Design approaches and tools in education and training (1999) 125-135. Springer, Dordrecht. DOI: https://doi.org/10.1007/978-94-011-4255-7_10

[22] I. Yuliarni, J. Marzal, E. Kuntarto. Analysis of Multimedia Learning Mathematics Storyboard
Design. International Journal of Trends in Mathematics Education Research, 2 (3) (2019) 149-152. 